\title{
Research on the Ideographic Functions of Affixes in Gan Language (Badu Dialect)
}

\author{
Xiao Jiugen ${ }^{1, ~ *, ~ Z h o u ~ Y i n g ~}{ }^{1}$, Chen Xijuan² \\ ${ }^{1}$ Jiangxi Normal University, College of Liberal Arts, Research Center of Language and Language Life, Nanchang, China \\ ${ }^{2}$ Nanchang Institution of Technology and Science, Nanchang, China
}

Email address:

jxsdxjg666666@sina.com (Xiao Jiugen),992963813@qq.com (Zhou Ying), 403744677@qq.com (Chen Xijuan)

${ }^{*}$ Corresponding author

\section{To cite this article:}

Xiao Jiugen, Zhou Ying, Chen Xijuan. Research on the Ideographic Functions of Affixes in Gan Language (Badu Dialect). Science Innovation. Vol. 6, No. 1, 2018, pp. 10-14. doi: 10.11648/j.si.20180601.13

Received: February 3, 2018; Accepted: February 23, 2018; Published: March 9, 2018

\begin{abstract}
The Badu dialect in Gan language belongs to Jicha area. After a long period of evolution, there are not only many differences between Badu dialect and Gan language, but also many differences with the dialect of its county town (Wenfeng town). The affixes are rich in Badu dialect and their ideographic functions are also varied with distinctive local characteristics. In order to show its features, here some common affixes of several kinds of words are selected in the research and make some preliminary analysis, which aims to reveal their colorful ideographic functions.
\end{abstract}

Keywords: Gan Language, Badu Dialect, Affix, Ideographic Function

\section{赣语（八都话）中几类词语缀的表意功能分析}

肖九根 ${ }^{*}$, 周颖 ${ }^{1}$, 陈䂀娟 ${ }^{2}$

1 江西师范大学文学院, 语言与语言生活研究中心, 南昌, 中国

2 南昌工学院, 南昌, 中国

\section{邮箱}

jxsdxjg666666@sina.com（肖九根），992963813@qq.com（周颖），403744677@qq.com（陈曦娟）

摘要：赣语中的八都话属于吉茶片。经过长期的嬗变之后, 八都话不仅与赣语存有许多不同之处, 就是与县城（文峰 镇）话也有不少差异。在八都话中, 语缀成分特别丰富, 其表意功能也多种多样, 独具鲜明的地方特色。为了展示其 特色, 这里倾择几类词中的一些常用语缀, 作些初浅的分析, 旨在揭示其多姿多彩的表意功能。

关键词：赣语, 八都话, 语缀, 表意功能

\section{1. 引言}

一代伟人毛泽东的祖籍地一一吉水县八都是一座历 史名镇, 史称“龙城”, 还在明朝永乐元年间就是一个经济、 文化十分发达的重要市镇。它位于江西吉水县城东北部, 地处吉（水）、永（丰）、峡（江）三县交汇点, 离省会
城市一一南昌 162 公里, 京九铁路纵贯全境, 交通十分便 利。

八都镇管辖 22 个行政村（共 128 个自然村），总人口 达40500多人（据2017年统计）。就镇政府所在地而言, 它是一个人居交杂的城镇, 除本地居民外, 还有来自本省 南昌、樟树、丰城、兴国及外省如广东、广西、浙江、湖 南、贵州、四川、江苏、安徽、河南、福建等地的居民。 
尽管语言品种复杂多样, 但是八都话始终是当地居民交际 的主要工具。

八都话属于赣语吉茶片。历经千百年嬗变之后, 八都 话不仅与赣语有许多不同之处, 就是与县城（文峰镇）话 也有不少差异, 无论语音、词汇还是语法方面, 都形成了 自己的特色, 而其中尤显多姿多彩的是其语缀的语法表意 功能。

二十一世纪以来, 方言语缀研究方兴未艾, 发表了不 少颇具份量的论文, 诸如汤志祥(2000)[1]、孙玉卿 (2002)

[2]、曾毅平 (2003) [3]、吴继章 (2005) [4]、郭辉 (2007)

[5]、侯超（2012）[6]、王曦（2014）[7]、马若宏（2015）

[8]、刘楚群 (2016) [9]、何亮 (2017) [10]等, 还出版了 国家社科项目方面的学术专著, 如蒋宗许 (2009) 等 [11]

(p304-310)。此外, 一些研究生也以方言语缀问题作为 学位论文选题, 如付婷 (2006) [12]、王立群 (2008) [13]、 郝漟 (2009) [14]等。不过, 虽然方言语缀研究成果不少, 然而赣语八都话的语缀问题迄今尚未涉猎, 尽管其语缀的 表意功能丰富多样。正是基于这一点, 我们就其几类词的 语缀问题作些描写, 旨在探讨其丰富的语法功能和语体色 彩。

文中的符号 “ $\square$ ” 指代有音无形的字词或语素。

\section{2. 前加语缀的语法功用}

1. 名词前缀

在赣语八都话中，常作名词前缀的有“老”、“毛”等。 (1) 老

“老”用作名词前缀最常见, 它附在亲属名词前, 表示 一种亲密的情感, 如丈夫、妻子可引称“老公、老婆”。此 外, 还有如: 老爹 $\left[\mathrm{tia}^{44}\right]$ 、老娘（可自称, 也可引称）、 老兄 $\left[\operatorname{cian}^{44}\right]$ (可面称哥哥, 也可引称）、老弟（弟弟的引 称）、老大 $\left[\mathrm{t}^{\mathrm{c}} \mathrm{a}^{\mathrm{3}} \mathrm{a}^{31}\right.$ 、老三、老六 (有时面称, 但多数是引 称）、老外 $\left[\mathrm{gai}^{53}\right]$ 婆、老舅 $\left[\mathrm{tchiu}^{213}\right]$ 、老姑婆（面称、引称 均可）。有时用“老”表示排行最末的，父母一般偏爱小儿 子, 把他视作掌上明珠, 常称之“老㩄”; 或者把晚年 (四 十岁之后) 才得的娇子叫做“老聕”, 即使独苗也如此称呼。 “老”还可以放在其他名词前面, 表示尊称或昵称, 如对年 龄大的称“老人家”、“老婆婆”等, 对陌生男子友好地称“老 表”, 把与自己同年生日且友好相交的称之为“老庚” (不 论性别），有些老年夫妻还会昵称自己的老伴为“我该老 个”。不过，有些词带上“老”字还有厌恶、讽刺、咒骂的 意味, 如: 老头或老子 (“老头子”的省称) 、老童生（讽 刺、挖苦那些年纪较大而学业上不思进取的男学生) 、老 后生（讱讽那些整日平平庸庸地打发日子的男青年）、老 相娘 (取笑那些过了该出嫁的年龄却还找不着对象的姑 娘）、老贼 $\left[\operatorname{tsh} \varepsilon^{31}\right]$ 牯（骂惯于偷窃的男子）、老贼婆（骂 惯于偷窃的女子)、老嫖客、老偷人婆（骂常与男人搞不 正当关系的女子)、老单身 (指年龄大却还未结婚的男子)、 老察妇、老绝 $\left[\mathrm{tchy} \mathrm{a}^{31}\right.$ ) 户 (骂人没有儿子传宗接代) 、老 $\square\left[\operatorname{tcien}^{44}\right]$ 棺材个（骂年老的人应该死去）。

(1)蒋宗许的《汉语词缀研究》第五章第二节 (p304-310) 就专论汉语方 言中缀 “里” “不” 的词例。
(2) 毛

“毛”也是口头上一个常用的名词前加成分, 它具有描 写性质，有“小”的意思。用它指称人，一般只用来称呼小 孩, 表示一种特别珍视、喜爱的情感, 如当地大人或长辈 常昵称小孩为“毛牙 $\left[\mathrm{ya}^{44}\right]$ 仔”、“毛岁 $\left[6 \mathrm{y}^{53}\right]$ 仔”，甚至对十 来岁的孩子也这样称呼。倘若称“老毛岁”, 就带有厌恶、 讽刺的意味了。家里长辈还喜欢把刚出生或出生不久的㚣 儿称为“毛牦 $\left[\mathrm{mau}^{31}\right]$ 仔”, 这可谓是非常亲切的爱称了。当 然，称人带“毛”的并不都有“喜爱”的色彩，有时还表示一 种厌恶的情绪, 称“毛女仔”、“毛崽仔”等就意味着“个头小， 不中看”，如“该毛女仔是个辣 $\left[1 \mathfrak{x}^{31}\right]$ 椒婆，骂鞄 $\left[\mathrm{sæ}^{44}\right]$ 人 $\left[\mathrm{nin}^{53}\right]$ 。“渠（他）闱里（家里）该毛崽仔死懒, 吃哩饭 啥个事总冒做 $\left[\mathrm{ts}^{53}\right]$ 。”不过, “毛”作动物名词前缀就更常 见, 一般用于家畜家禽, 表示幼小、喜爱的感情, 如: 毛 鸡仔、毛鸭 $\left[\mathrm{yæ}^{44}\right]$ 仔、毛鹅 $\left[\mathrm{yo}^{53}\right]$ 仔、毛狗仔、毛猪 $\left[\mathrm{ty}^{44}\right]$ 仔、 毛牛仔......而鸽、猫、羊、马称“毛”的不多, 大多是前面 加个“小”字，称“小鸽”、“小猫”等，野生动物也没有“毛-” 的叫法。有时侯, “毛”还可以用于天气, 虽带有描写性质, 却无所谓感情色彩了, 如把“下小雨”说成“落毛雨仔”, “下 雪”说成“落毛雪 (不论大小) ”。

\section{2. 动词前缀}

八都话中，常作动词前缀的有“紧”，用在动词前表示 动作的持续或反复, 而且含有长时间不断地持续某种动作 的意味, 它的出现率很高。如: 老师 $\square\left[\mathrm{tchi}^{53}\right]$ 哩讲 $\left[\mathrm{kog}^{213}\right]$ 课, 该崽还紧话 $\left[\mathrm{ua}^{31}\right]$ 事 (老师正在上课, 那小孩还在不 停地说话）。渠爹 $\left[\mathrm{tia}^{44}\right]$ 仔喊门, 紧冒哪个开门（他爸爸 叫门, 没有哪个人开门)。该花勒衣裳紧浸, 啥个烂 $\square\left[\mathrm{pho}^{44}\right]$ 哩 (那些衣服长时间地浸, 什么东西都会烂掉)。该隻 $\left[\mathrm{ta}^{44}\right]$ 老天公公紧落 $\left[10^{31}\right]$ 雨, 舞得我做事总做不 $\square\left[\tan ^{53}\right]$ （那老 天爷长久下雨，弄得我做事也做不成）。

为了强调动作的反复和持续, “紧+V (动) ”可以重叠 为“紧 $V$ 紧 $V$ ”。如: 该隻老子紧咳紧咳, $\square\left[\mathrm{ia}^{31}\right] \square\left[\mathrm{pcu}^{53}\right]$ 是得哩啥个病 (那老头老是咳嗽, 说不定是得了什么病)。 气憊人, 该隻崽紧哭紧哭, 俺话总话不当 (气死人, 那男 孩老是哭，我说都说得没用）。

“紧 $\mathrm{V}$ 总 $\mathrm{V}$ 不”表示动作无论如何怎么持续进行，总不 能达到预期的效果。如: 紧教 $\left[\mathrm{kau}^{53}\right]$ 总教不熟（怎么教也 教不会）。紧行 $\left[\mathrm{han}^{53}\right]$ 总行不到（怎么走也走不到）。紧 灌总灌不醉 (怎么灌也灌不醉)。紧洗总洗不光 (怎么洗 也洗不干净）。

\section{3. 形容词前缀}

八都话中, 常作形容词前缀的有“真”、“死”、“忒”、“几” 等, 都是表示性状程度的。

(1) 真

“真 $\left[\operatorname{tin}^{44}\right]$ ”作形容词的前加成分出现的频率很高, 它 相当于一个副词，有“非常”之意，如“真热”。为了进一步 加强语气程度, 它往往与“个”结合使用, “真个-”有普通话 后加成分“-极了”或“-得很”之意。它既可用于襄义方面, 如: 真个好（好极了、好得很）、真个甜（甜极了、甜得 很）、真个红、真个绿、真个舒服、真个高兴、真个好过、 真个富裕、真个能干、真个热闹、真个光亮、真个溜滑 $\left[u æ^{31}\right]$; 也可用于贬义方面, 如: 真个热（热极了、热得很）、真 个冷 $\left[\operatorname{liay}^{31}\right]$ （冷极了、冷得很）、真个慢、真个慌、真个 
恶 $\left[\mathrm{no}^{44}\right]$ 、真个头痛、真个烦躁、真个狠、真个毒、真个 黑; 也有贬词襄用的, 如“真个奸 $\left[\mathrm{kan}^{44}\right]$ ”一语, 在当地一 般不作“阴险奸诈”义，而是崇尚某人足智多谋，如“该隻 后生真个奸, 啥个事总晓得做”。

(2) 死

“死”作形容词前加成分出现的频率也高, 它相当于普 通话的“过于、太”之意。在语气上，其程度似乎比“真”还 要重些, 大概等于“真个”的程度, 如“死不要面（脸）”。 不过，与“真个”用法不同的是它一般只用在不好的方面, 带有埋怨、不满的意味, 如: 死热、死冷、死慢、死蚌、 死重、死懒、死不愿意、死强、死胖、死蛮.....如果“死” 带上单音节形容词的重叠式及中缀成分, 它的语意程度又 有所加强, 如: 死慢哩慢、死重哩重、死奸哩奸......颜色 词“红”、“绿”等不能带“死”这个前加成分, 而“黑”、“黄 $\left[\mathrm{uan}^{53}\right] ” 、 “$ 白 $\left[\mathrm{pha}^{31}\right]$ ”等却又能带, 还能带重叠式及中加成 分, 如不能说“死红”、“死绿”, 却能说“死黑”、“死黄”、“死 白”或者“死黑哩黑”、“死黄哩黄”诸如此类。

(3) 忒

“忒”也是形容词用得较多的一个前加成分, 它表示程 度过分，相当于普通话“太”义。不过，普通话“太”除表示 程度过分外，还有不表示过分的用法，如“太好了”、“太 妙了”、“太美了”等, 而八都话“忒”却没有后一种用法, 如: 渠闱里细人式多哩（他家小孩太多了）。该相人式厉害哩 （该妇女太厉害了）。一个人忒精哩也不好（一个人太精 明了也不好）。

(4) 几

“几”本来是个表数字的疑问词, 但它附在形容词前表 示程度高或深，其作用相当于一个程度副词，有“多么”、 “很”之意, 如: 几白、几规矩、几闹热、几跑火（行业或 生意等非常受人欢迎）、几行 $\left[\mathrm{han}^{53}\right]$ 时（很走运）、几贅 $\left[\mathrm{pau}^{53}\right]$ 气（很横暴）、几擞 $\left[\mathrm{phi} \varepsilon^{44}\right]$ 得（很爽快）、几抛轻 (很轻) ......还可以在“几+A（形）”后加上语气词表示一 种强烈的语气，如“你 $\square\left[\mathrm{piau}^{53}\right]$ 惹 $\left[\mathrm{nia}^{213}\right]$ 渠（你不要惹他）, 该隻（个）后生几聱气呀! “昨日当新街（当地人把五月 初四赶集叫做“当新街”），街上几多人啦！”

除此之外, 具有地方特色的形容词前加成分还有一些, 只是它们与别的前加成分有些不同而已。它们是一种固定 的习惯搭配, 不是自由组合的, 常活跃在人们的口头上, 如: $\square\left[\tan ^{44}\right]$ 光（很光亮）、溜滑 (很光滑)、津甜（很 甜)、揪酸（很酸）、寡淡 (味道很淡) 、抛轻 $\left[\mathrm{tchiaj}^{44}\right]$ (重量很轻)。它们还可以重叠并附上后缀, 极言程度之 强或弱, 如: $\square\left[\tan ^{44}\right]$ 光 $\square\left[\tan ^{44}\right]$ 光哩、溜滑溜滑哩、揪酸 揪酸哩、寡淡寡淡哩、抛轻抛轻哩。

\section{3. 后加语缀的语法功用}

\section{1. 名词后缀}

在八都话中, 名、动、形容词的后缀十分丰富。这里 仅举最为常见的几例以略加说明。

(1) 哩

“哩”能作各类词的后加成分, 最为常用的是作名词、 动词、形容词的后加成分。
“哩”作名词的后加成分, 出现在部分名词词素后面构 成名词, 如: 裤哩 (裤子) 、麻哩 (麻子)、粉哩 (粉丝) 、 舌哩（舌头）、眼哩（眼睛）、帐哩（蚊帐）、瘌哩（秃 头）、点界哩（中午）、夜布星哩（夜晚）、竹叶哩（竹 叶)、短脚裤哩 (短裤) 、锯屑哩 (锯末) ......甚至有些 非名词语言单位 (个别动词词素) 之后加上“哩”, 也能构 成名词, 如: 嵌哩（戒指）、磨哩（磨盘）。

(2) 个

“个”字一般是作量词, 但在八都话中却有许多其他用 法，尤其作词的后加成分最为常见，相当于普通话“的”字 结构。如: 我个 (我的或我们的)、你个 (你的或你们的)、 渠个（他的或他们）、重个（重的）、短个（短的）、吃 个（吃的）、穿个（穿的）。

下面分几方面说明其用法:

(1)“个”在形容词后既可指人，也可指物，这使整个短 语变成了名词性的, “个”就成了一个构词语素。如: 高个 (指高的人或物) 、矮个 (指矮的人或物) 、轻个（指轻 的人或物）、大个（指个头大或年龄大的人，大物件）、 细个（指个头小或年龄小的人，小物件）、瘦个（指瘦的 人或动物）。

(2)“个”在动词后只能指物, 不能指人, 这也使整个短 语变成名词性的了, “个”也是一个构词语素。如: 看个 (指 看的东西)、卖个 (指卖的东西) 、买个 (指买的东西) 、 做个（指做的东西）、哇个（指说的事情, “该只事是人 家哇个”）、读个（指读物）。

(3)“个”在带有动词词组后既可指人, 也可指物, 整个 短语也变成了名词性的, “个”仍是名词的构词语素。如: 冒屋住个（指没有住房的人或户）、冒田个（指无地农民 或农户）、接生个（指接生婆或接生工具）、作田个（指 农民、农户或农具）、担担个（指挑担者或挑具）、赚钱 个（指赚钱的人或赚钱的买卖）、剃脑个（指理发师或理 发工具）、派出所个（指警察或派出所的东西）、唱戏个 （演戏的人或演戏的导具）。

(3) 仔

“仔”在当地一般读t这个音, 它作名词后缀的使用范 围较广, 既可用于有生命性的东西, 又可用于无生命性的; 既可带感情色彩, 又可不带感情色彩。一般地说, “仔”用 于表示人的名词后, 有些带有小而爱怜的意味, 如: 脚崽 仔 (称小儿子) 、脚女仔 (称小女儿)、孙仔 (称男孙) 、 孙女仔、妹仔 (妹妹) 、老弟仔、后生仔。

有些则表示一种尊敬、亲热的感情, 如: 爹仔(父亲)、 娘仔（母亲）。但如是“老师仔（自嘲或讱讽做老师的无 权无势又无钱，没有能力办成什么大事）”、“六只仔（六 个指头的人) ”、“拐脚仔 (拐腿的人) ”、“缺子仔（口缺 的人) ”等, 则明显含有轻㧛、讽刺意味。

“仔”用于表示动物名词后, 多数情况下也带有一种主 观意念上认为小而喜爱的语意色彩, 如: 毛鸡仔 (小鸡) 、 毛鸭仔、毛鹅仔、毛猪仔、毛狗仔、毛牛仔、马仔、羊仔、 鸽仔、猴仔、蚕仔、兔仔......而有时却不一定含有这样的 意思, 如“豹虎仔 (豹子) ”、“蛛蛛仔 (蜘蛛) ”、“泥蛇仔 (蝶蚓) ”等, 这实际上带有一种厌恶的感情。

“仔”还大量地用于其它没有生命的事物名词后，它无 所谓带有何种感情, 仅是一种习惯用法而已, 如: 椅仔 (椅 
子）、钉仔（钉子）、裬仔（上衣）、帽仔（帽子）、鞋 仔 (鞋子) 、笔盖仔 (笔帽)、茄仔 (茄子) .......这样的 例子举不胜举。

\section{(4) 子}

作为名词后缀, “子”的应用范围也很广。“子”附在一 些名词性词根后构成名词, 如: 筷子、底子、银子、饺子、 星子、建子、狮子、土车子、料子 (好布料) 、面子、法 子、皮子、腰子、架子 (作具体名词或抽象名词) .......尒” 附在一些谓词性词根后也能构成名词, 如: 瞎子、蚌子、 夹子、拐子 (拐骗钱财的人) 、矮子、老子 (骄傲的人自 称）、勾鼻子（具有鹰勾鼻特性的男人，含讽刺意）、 $\square$ $\left[\mathrm{ma}^{44}\right]$ 鼻子 (塌鼻子的男人, 有轻视意味) 。不过, 有些 名词只能带“子”尾, 而不能带其它别的什么, 如“狵子”、 “哑巴子”等。

(5) 头

“头”是当地口语里用得较多的一个后加成分, 它作后 缀构成名词的方式多种多样。或在单音名词语素后加上 “头”尾, 构成双音化名词, 如: 肩头（肩膀）、症头（病 症）、日头（太阳）、石头、砖头; 或在单音动词语素后 加上“头”尾, 构成双音化名词, 如: 吃头、看头、奔头、 做头、想头、结头（结子）; 或在单音形容词语素后加上 “头”尾, 构成双音化名词, 如: 苦头、甜头、光头 (秃头); 或在单音方位词后加上“头”尾, 构成双音化名词, 如: 上 头（指方位上面或上级领导机构）、下头（指方位下面或 下级部属)、里头（里面）、外头 (外面)、前头（前面）。

（6）佬

“佬”也可作名词后加成分, 它一般用来表示某一地域 或某一行业的人, 大多含有不敬或蓝视的意味, 如: 乡下 佬、外地佬、策佬（䉝匠）、铁佬（铁匠）。当然, 它出 现的频率不是很高。

2. 动词、形容词后缀

(1) 哩

“哩”作动词后加成分, 表示某种动作已经完成的语法 意义, 相当于普通话的“了”, 如: 风停哩 (风已经停了)、 雨醒哩（雨已经停了）、雪融哩（雪已经化了）、水浸哩 （水已经淹了）、呕哩（已经吐了）、死哩（已经死了）、 做哩（已经做了）、吃哩（已经吃了）。

作形容词后加成分, 它表示已经出现了某种状态, 而 且某种状态还有持续下去的可能, 如: 疋红哩 (疋红了)、 天暗哩 (天黑了)、叶青哩 (叶绿了)、脚肿哩 (脚肿了)、 水热哩 (两层含义: 一指水过于热㵣, 二指水的热度恰好 适合使用）。

有一种情况值得一提, “哩”还常附在动词或形容词补 语后表示某种情状已经出现, 并带有一种肯定的语气, 如: 做好哩、出去哩、转来哩 (回来了) 、碰倒哩 (一是遇见 了, 另一是碰撞倒了) 、跌倒哩（摔倒了）、塞倒哩（哽 住了)、将杀哩 (下象棋语, 将死了)、热熟哩 (热透了)、 冷坏哩（病了）、痛死哩、胀破哩（指肚子发胀, 而且很 厉害）。

还有另外一种情况也值得一提, 就是说“哩”还可作副 词性词尾, 出现在部分双音词素后构成副词, 如: “我硬 要好好哩话渠一餐（我一定要好好地说他一顿）。”“俺要
死死哩 $\square \mathrm{k}^{6} \mathrm{a}^{44}$ 住该隻 $\mathrm{ta}^{44}$ 贼牯（我们要死死地抓住那个 贼）。”洞要深深哩挖。”

(2) 要死 要命 不得了

“要死”、“要命”、“不得了”作动词、形容词后加成分 意义大体相当, 完全可以相互替换, 都是用来表示动作、 状态的程度, 如: 热得要死 (要命、不得了) 、想得要死 (要命、不得了) 、怕得要死（要命、不得了）。诚然, 它们各自出现的频率是不同的, 一般说来, “要死”、“要 命”在口语里更为常用。这种后加成分大多用于不好的方 面, 如: 闷得要死 (要命、不得了) 、冷得要死 (要命、 不得了) 、痛得要死 (要命、不得了) 、蚌得要死、气得 要死 (要命、不得了)、哭得要死 (要命)、打得要死 (要 命）。不过, 也可用于好的方面, 只是要少些, 如: 兴得 要死 (要命、不得了) 、香得要死 (要命、不得了) 、笑 得要死 (要命、不得了) 。

除了上述常见的后加成分外，还有“死哩”和“繁哩”。 它们也作动词、形容词后加成分, 意义几乎相等, 可以互 换用来表示动作、状态的程度, 只是后者在口语中用得更 多, 如: 兴繁哩（死哩）、热整哩（死哩）、笑繁哩（死 哩) ...... 一般说来, 只要去掉例中的“得”字, 其用法与“要 死”或“要命”就没有什么差别了。

\section{4. 结论}

以上分析的仅是其中最常见的几类词的语缀所表现 出来的语法功能。从这几类词的语缀所表现出来的语法功 能看, 它具有以下特点:

第一, 语缀的前加成分, 多是与名词性、动词性和形 容词性等词根语素结合在一起的, 它们各自表现出不同的 语法功能。名词性语缀一般具有描写的性质, 用于称谓时 大都表示亲切、喜爱之类的思想情感; 而动词性语缀, 则 一般表示某种行为动作长时间而又不间断的反复进行; 最 为丰富的是形容词语缀, 其语法功能虽各不相同, 然却表 现出一个共同的特点, 那就是均表示事物在某种程度上加 强之意味。

第二, 语缀的后加成分也如前加成分一样, 大多附于 名、动、形三类词根语素之上, 表示各种复杂多样的语法 意义。有的语缀, 可以同时作几类词的后加成分, 不仅表 现出不同的语法意义, 而且往往还具有构成新词或改变词 性的语法作用; 有的语缀则带有一定的情感色彩, 也有不 带任何情感色彩的, 只是人们习惯如此使用而已。

第三, 有的后加语缀与同一词类中的单音词素组合时, 只能指称物而不能指称人; 但与同一词类的双音或多音词 素组合时, 则可兼而称之。还有一类后加语缀, 无论与动 词、形容词、方位词等中的那一类单音词素进行组合, 都 将毫无例外地成为名词的构词语素。

一言以蔽之, 赣语八都话中的语缀现象十分丰富, 其 表现出来的语法功能以及色彩意义摇电多姿, 真正彰显出 其所独具的地方特色。 


\section{参考文献}

[1] Tang Zhixiang. Common Suffixes in Cantonese [J]. Dialects, 2000(4).

[2] Sun Yuqing. The Affixes of Datong Dialect "Hu" [J]. Dialect, 2002(4).

[3] Zeng Yiping. Common Noun Affixes in Shicheng (Longgang) Hakka Dialect [J]. Dialect, 2003(2).

[4] Wu Jizhang. The Tendency of the Development of Affixes in Hebei Dialect and the Function of Semantics in them[J]. Research on Language, 2005(1).

[5] Guo Hui. Research on the Affix "Zi" in Suixi Dialect of the Northern Anhui [J]. dialects of Suixi dialect [J]. Dialect, 2007(3).

[6] 侯超. 汉语词缀的功能与皖北方言的 “子” 尾 [J]. 南京师范 大学文学院学报2012(3)。

[7] 王曦. 明嘉靖本《荔镜记》方言词缀研究 [J]. 东南学 术, 2014(2)。

[8] Ma Ruohong, Zhang Siyao. Analysis of the Suffix "Zi" in Ninghua Hakka Dialect [J]. Modern Chinese,2015(5).

[9] 刘楚群 陈波. 新兴亲属义类词缀探究 $[J]$. 江西师范大学学 报, 2016（6）。

[10] He Liang. Time Expression System of Chinese Dialect "Yesterday", "Today", "Tomorrow" and its Source [J]. Chinese Language, 2017(5).

[11] Jiang Zongxu. Study of Chinese Affixes [M]. Sichuan Publishing Group, Bashu Book Publishing Co., Ltd. 2009.

[12] Fu Ting. Study on Affixes of Zhangshu Dialect[D]. Nanchang: Thesis of Master's Degree in Jiangxi Normal University, 2006.

[13] Wang LIqun. A Typological Study of Affixes in Chinese Dialects[D]. Beijing: Thesis of Master's Degree of Capital Normal University, 2008.

[14] Hao Ying. Study on Affix in Linfen Dialect [D]. Thesis of Master's Degree in Tianjin Normal University, 2009. 